\title{
THIELAVIN A AND B, NEW INHIBITORS OF PROSTAGLANDIN BIOSYNTHESIS PRODUCED BY THIELAVIA TERRICOLA
}

\author{
Nobuaki Kitahara, Akira Endo, * Kohei Furuya \\ and SHUJ TAKAHASHI \\ Fermentation Research Laboratories, Sankyo Co., Ltd., \\ 1-2-58 Hiromachi, Shinagawa-ku, Tokyo, 140 Japan \\ *Department of Agricultural and Biological Chemistry, Tokyo Noko University, \\ 3-5-8 Saiwaicho, Fuchu-shi, Tokyo, 183 Japan
}

(Received for publication August 29, 1981)

\begin{abstract}
Two potent inhibitors of prostaglandin biosynthesis, thielavin $A\left(\mathrm{C}_{31} \mathrm{H}_{34} \mathrm{O}_{10}\right)$ and $\mathrm{B}$ $\left(\mathrm{C}_{20} \mathrm{H}_{30} \mathrm{O}_{10}\right)$, were isolated from cultures of Thielavia terricola. Both of these compounds were shown to be structurally related to depsides, thus consisting of three hydroxybenzoic acid groups. Concentrations required for $50 \%$ inhibition of the conversion of ${ }^{14} \mathrm{C}$-arachidonic acid into prostaglandins $\mathrm{F}_{2 \alpha}$ plus $\mathrm{E}_{2}$ by microsomes of ram seminal vesicles were $12 \mu \mathrm{M}$ for thielavin $\mathrm{A}$ and $9 \mu \mathrm{M}$ for thielavin $\mathrm{B}$, respectively. Of the enzymatic steps involved in prostaglandin synthesis, thielavin A specifically inhibited the conversion of arachidonic acid into prostaglandin $\mathrm{H}_{2}$, while prostaglandin $\mathrm{E}_{2}$ synthesis from the endoperoxide was the most sensitive to thielavin B.

Thromboxane $\mathrm{A}_{2}$ synthesis from prostaglandin $\mathrm{H}_{2}$ in bovine platelet microsomes were inhibited by $50 \%$ at concentrations of 150 and $350 \mu \mathrm{M}$ of thielavin A and B, respectively.

Thielavin B was significantly effective on carrageenan-induced oedema of rats when administered intravenously but not on oral administration. The anti-inflammatory activity was not detectable with thielavin A either on intravenous injection or on oral administration.
\end{abstract}

Non-steroidal anti-inflammatory agents like aspirin and indomethacin are known to specifically inhibit prostaglandin synthetase..$^{1 \sim 3)}$

During a search for specific inhibitors of prostaglandin synthesis of microbial origin, xanthocillin $\mathrm{X}$ monomethyl ether as a potent inhibitor was isolated from cultures of Dichotomomyces cejpii. ${ }^{4}$ )

Further study has resulted in the isolation of two active compounds (thielavin A and B) from cultures of Thielavia terricola.

The present paper deals with identification of the producing organisms and production and isolation of thielavin A and B as well as their physicochemical properties and biological activities. The results of studies dealing with the structural elucidation of these inhibitors will be reported in a subsequent paper.

\section{Materials and Methods}

Chemicals

$1-^{14} \mathrm{C}$ Arachidonic acid $(61.0 \mathrm{Ci} / \mathrm{mole})$ was obtained from New England Nuclear and unlabeled arachidonic acid (grade 1), prostaglandin $\mathrm{F}_{2 \alpha}$ and $\mathrm{E}_{2}$, reduced glutathione and L-tryptophan from Sigma, bovine hemoglobin from Tokyo Kasei, imidazole and silica gel (Wako gel C-200) from Wako Pure Chemical Industries. Indomethacin was kindly given by Dr. E. Misaka of this laboratory.

* All correspondence should be addressed to Dr. AKIRA Endo at Department of Agricultural and Biological Chemistry, Tokyo Noko University, 3-5-8 Saiwaicho, Fuchu-shi, Tokyo, 183 Japan. 


\section{Culture Medium}

Fermentation medium for the production of thielavin A and B contained $10.0 \%$ soluble starch, $1.5 \%$ Pharmamedia (Traders Protein), 2.0\% corn steep liquor (Corn Products Co.), 1.0\% meat extract, and $0.02 \%$ Disfoam CB 442 (Nippon Yushi Co.) an anti-foam agent.

Enzyme Preparations and Enzyme Assays

The microsomal fraction of ram seminal vesicular glands was obtained by the method of NUGTEREN et $a{ }^{57}$ and used to assay the synthesis of prostaglandins as described previously. ${ }^{4)}$ The microsomal fraction of bovine platelets was prepared according to the method of Yоsнімото et al. ${ }^{\text {b) }}$ and used to assay thromboxane synthesis from ${ }^{14} \mathrm{C}$-prostaglandin endoperoxide $\left(\mathrm{H}_{2}\right)$, prepared from ${ }^{14} \mathrm{C}$-arachidonic acid according to the method of UBATUBA et al. ${ }^{7)}$

Anti-inflammatory Activity

Anti-inflammatory effects on carrageenan-induced oedema of the rat foot pad were determined using male Wistar-Imamichi rats as described previously.4)

\section{Results and Discussion}

\section{Identification of Producing Fungus}

The fungus SANK 15876, which produces thielavin A and B, was freshly isolated from a soil sample collected in Thailand.

The mycological characteristics of this fungus are as follows: Colonies on WeItZMAn and SilvaHUTNER's agar ${ }^{8)}$ are attaining a diameter of 6 to $7 \mathrm{~cm}$ in 10 days at $26^{\circ} \mathrm{C}$, which are white and cottony with thin aerial mycelia, and afterwards produce perithecia abundantly as grayish dots. The reverse is uncolored. Growth at $37^{\circ} \mathrm{C}$ was nearly the same as at $26^{\circ} \mathrm{C}$, but perithecial production was less than that of $26^{\circ} \mathrm{C}$. The perithecia are superficial, spherical, glabrous, $50 \sim 220 \mu$ in diameter and gray to nearly black at maturity. The cells of peridium are membranaceous to pseudoparenchymatous, thin and semi-transparent. The asci are ovate, 8-spored, $20 \sim 26 \times 15 \sim 18 \mu$ and evanescent. The ascospores are ellipsoid, $12 \sim 17 \times 7 \sim 8 \mu$, smooth, at first hyaline, then becoming dark olive to olive brown, with a distinct apical germ pore at one end. No conidial structures are observed.

From the mycological characteristics described above, the fungus was identified as Thielavia terricola (Gilman et Abbott) Emons. ${ }^{9 \sim 12)}$

Fermentation

Thielavia terricola SANK 15876 was aerobically grown at $26^{\circ} \mathrm{C}$ in a 30-liter fermentor containing 18 liter of culture medium, inoculated with 2 liters of seed culture, under an aeration rate of 18 liters/minute and agitation at 150 r.p.m.. Under these conditions, production of the active principles reached maximal levels after 48 hours (Fig. 1.).

Fig. 1. Time course of thielavins fermentation.
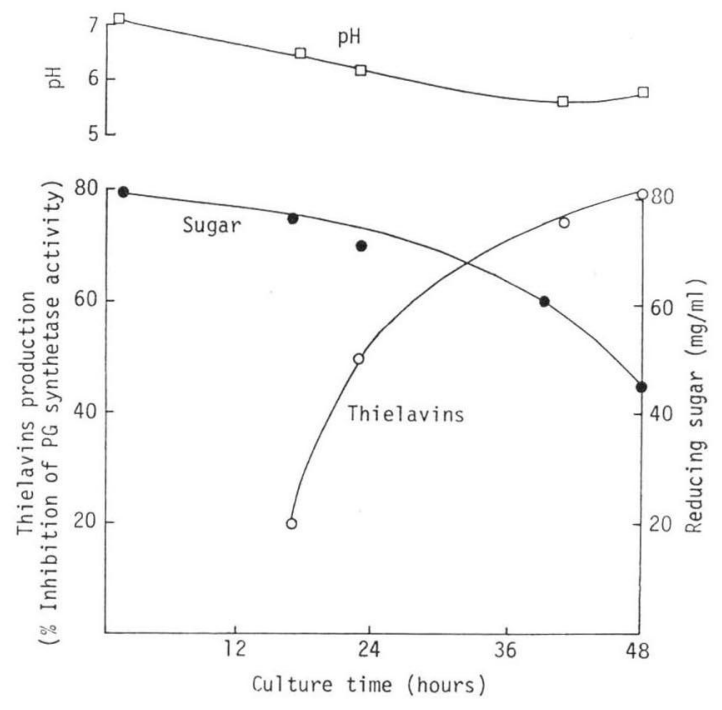

Isolation of Inhibitors

The inhibitory principles were found to be located in the mycelia but not in the culture filtrate. 
After 48 hours of growth mycelia of Thielavia terricola SANK 15876 were collected by filtration from 2 cultures of 30-liter fermentor, and the mycelial mat obtained ( $3.8 \mathrm{~kg}$ wet weight) was extracted with 10 liters of acetone at room temperature for 30 minutes. The mixture was filtered and the resultant filtrate was concentrated in vacuo to remove acetone. The aqueous solution obtained (2 liters) was adjusted to $\mathrm{pH} 2.0$ with $\mathrm{H}_{3} \mathrm{PO}_{4}$ and extracted twice with 1 volume of ethyl acetate. The solvent layers collected were concentrated in vacuo, yielding $25 \mathrm{~g}$ of oily fraction. The oily residue was applied to a column of silica gel C-200 $(3 \times 60 \mathrm{~cm})$ equilibrated with benzene $-n$-hexane $(1: 1)$, and after washing with 1 liter of benzene, the column was developed with $1 \%$ ethyl acetate in benzene. Fractions containing thielavin B were pooled and concentrated in vacuo to dryness, giving $2 \mathrm{~g}$ of white powder. The powder resulting was dissolved in $n$-hexane from which solution thielavin $\mathbf{B}$ was obtained as crystals $(1.2 \mathrm{~g})$.

After elution of thielavin B, the column was developed with ethyl acetate - benzene (1:1), and the active fractions were pooled and concentrated in vacuo to dryness, giving $1 \mathrm{~g}$ of yellowish powder. This powder was rechromatographed on a silica gel column $(2.6 \times 50 \mathrm{~cm})$; the column was developed as described above. Under these conditions, one major active fraction and one minor active fraction were eluted by development with ethyl acetate - benzene (1:1). To the major fraction was added $n$-hexane and the resultant crystals (thielavin A) were isolated and dried $(0.51 \mathrm{~g})$.

Physico-chemical Properties of the Thielavins

Thielavin A and B were obtained as colorless needle crystals from acetone. Melting points were $235 \sim 236^{\circ} \mathrm{C}$ and $250^{\circ} \mathrm{C}$ for thielavin $\mathrm{A}$ and $\mathrm{B}$, respectively, and both substances showed no optical rotation. These compounds were soluble in methanol, ethanol, butanol, acetone, ethyl acetate, butyl acetate, ethyl ether, chloroform, dioxane, dimethyl sulfoxide, and pyridine but almost insoluble in water, benzene, and $n$-hexane.

Fig. 2. UV spectra of thielavin A.

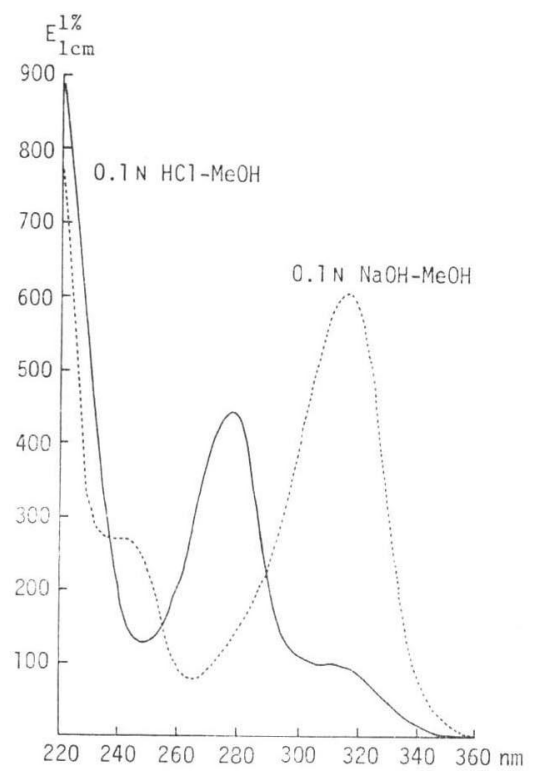

Fig. 3. UV spectra of thielavin B.

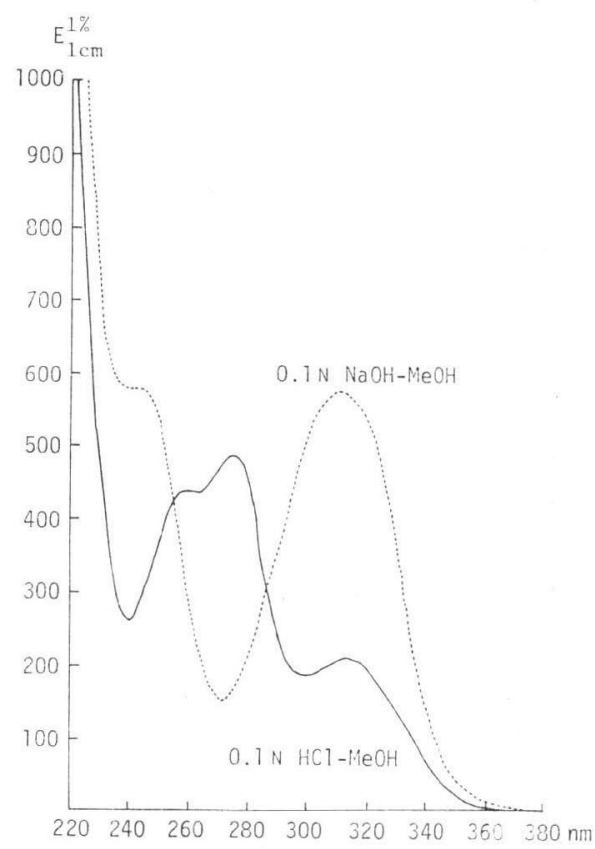


Fig. 4. IR absorption spectrum of thielavin $\mathrm{A}(\mathrm{KBr})$.

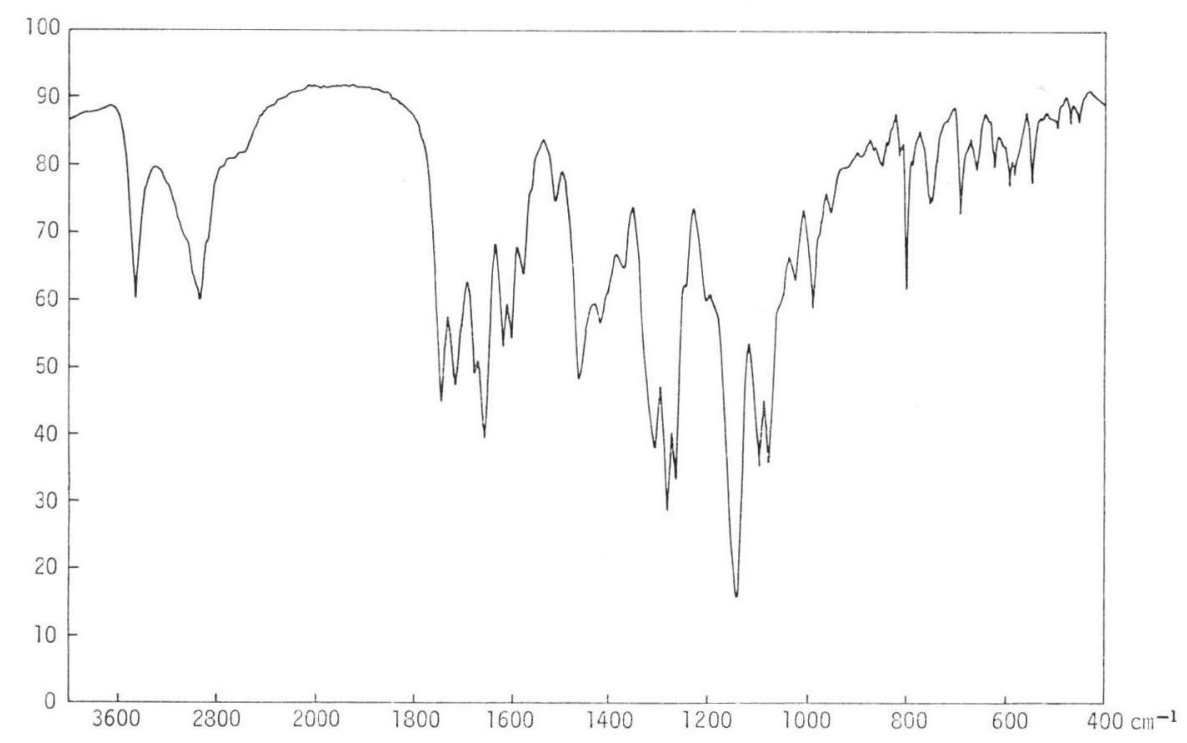

Fig. 5. IR absorption spectrum of thielavin $\mathrm{B}(\mathrm{KBr})$.

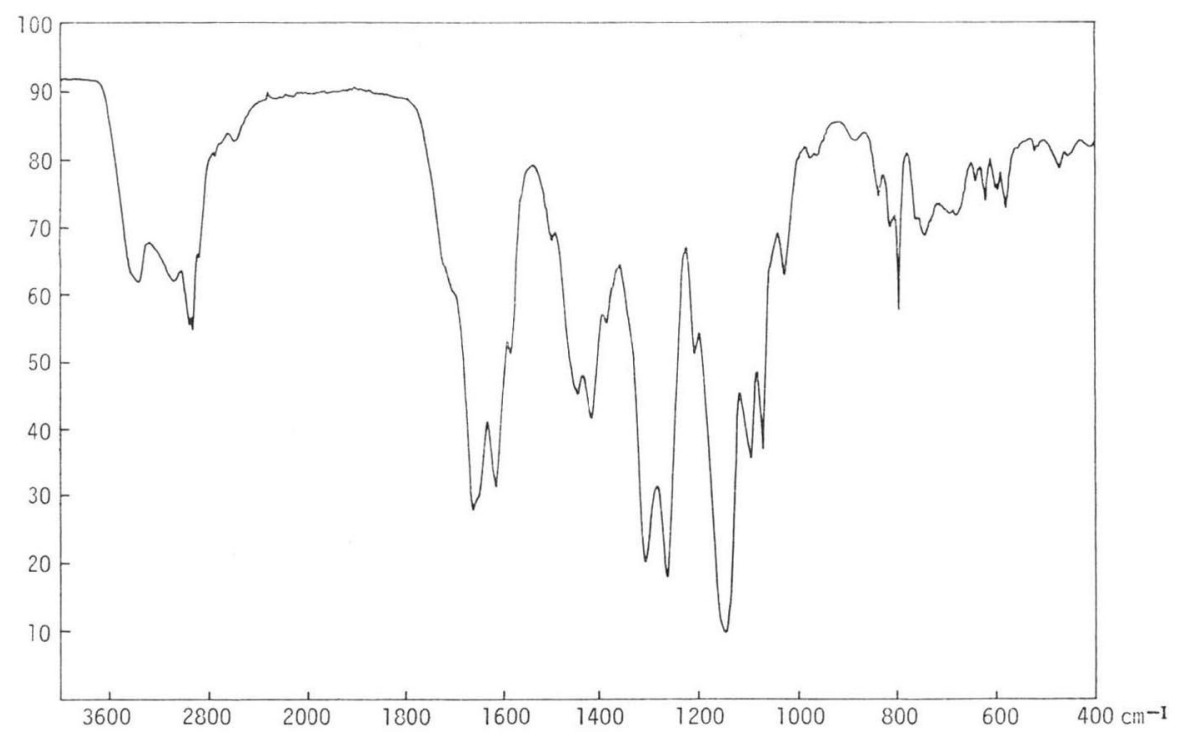

Both thielavin A and B were positive to ammonia phosphomolybdate, potassium ferricyanide - ferric chloride, and hydroxamic acid - ferric chloride, $\mathrm{KMnO}_{4}$, but negative to ninhydrin, FeHLING and MoLISH reactions. The UV spectra of thielavin A and B are shown in Figs. 2 and 3, respectively. Thielavin A had absorption maxima at $277 \mathrm{~nm}\left(\mathrm{E}_{1 \mathrm{~cm}}^{1 \%} 445\right)$ and $310 \mathrm{~nm}\left(\mathrm{E}_{1 \mathrm{~m}}^{1 \%} 100\right)$ in methanol or $0.1 \mathrm{~N} \mathrm{HCl}$ - methanol, and at $241 \mathrm{~nm}\left(\mathrm{E}_{1 \mathrm{~cm}}^{1 \%} 270\right)$ and $315 \mathrm{~nm}\left(\mathrm{E}_{1 \mathrm{~cm}}^{1 \%} 605\right)$ in $0.1 \mathrm{~N} \mathrm{NaOH}$ - methanol.

Thielavin B showed absorption maxima at $260 \mathrm{~nm}\left(\mathrm{E}_{1 \mathrm{~cm}}^{1 \% \%} 440\right), 274 \mathrm{~nm}\left(\mathrm{E}_{1 \mathrm{~cm}}^{1 \%} 490\right)$ and $314 \mathrm{~nm}\left(\mathrm{E}_{1 \mathrm{~cm}}^{1 \% \%}\right.$ $210)$ in methanol or $0.1 \mathrm{~N} \mathrm{HCl}$ - methanol, and at $243 \mathrm{~nm}\left(\mathrm{E}_{1 \mathrm{~m}}^{1 \%} 580\right)$ and $310 \mathrm{~nm}\left(\mathrm{E}_{1 \mathrm{~cm}}^{1 \%} 570\right)$ in $0.1 \mathrm{~N}$ 
Fig. 6. PMR of thielavin A (in pyridine).

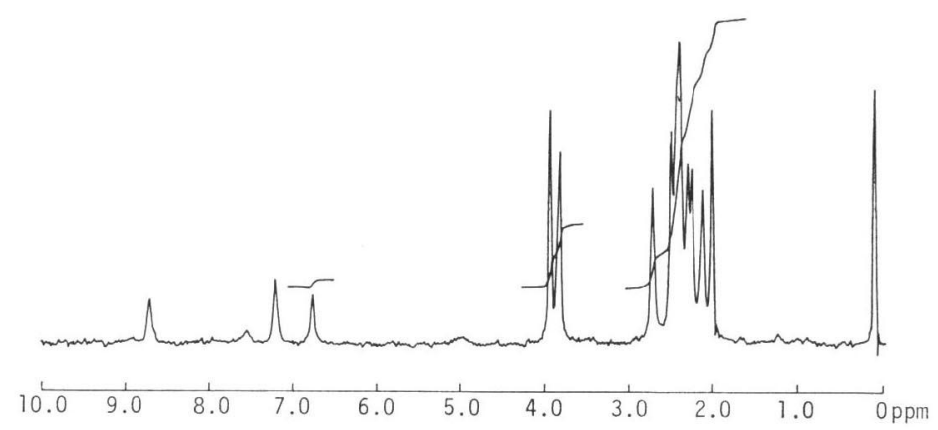

Fig. 7. PMR of thielavin B (in pyridine).

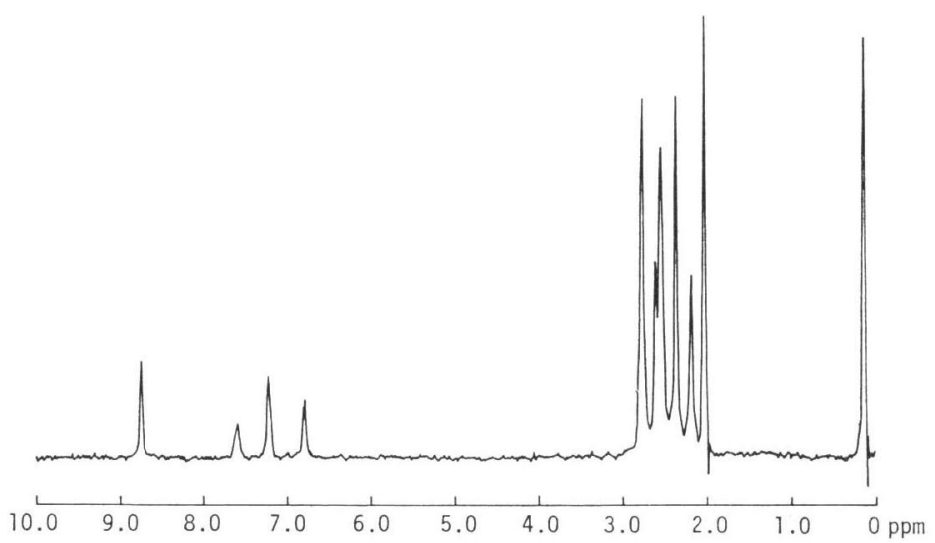

Fig. 8. CMR of thielavin A.

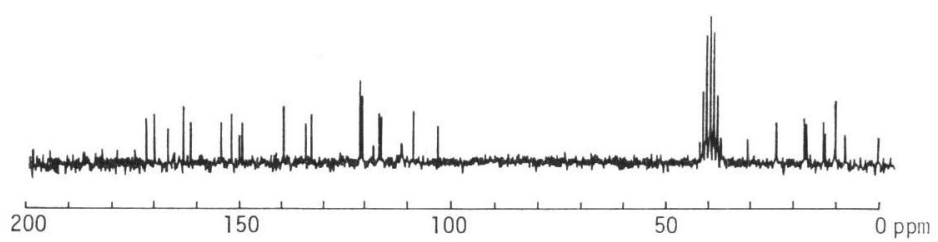

Fig. 9. CMR of thielavin B.

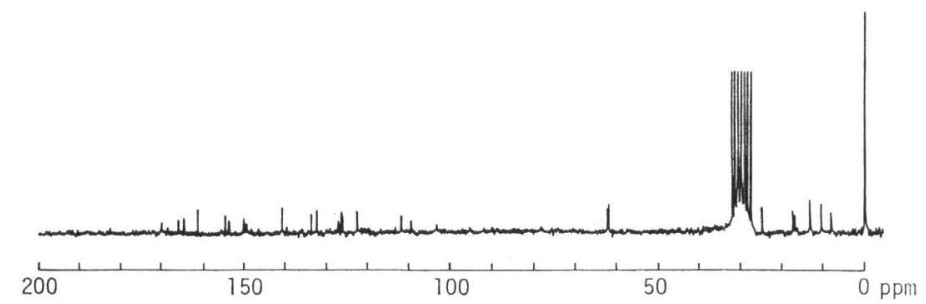


Fig. 10. Partial structure of thielavin A and B.

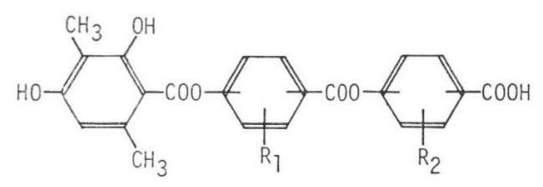

Thielavin $A: R_{1}=R_{2}=\mathrm{CH}_{3} \times 3, \mathrm{OCH}_{3} \times 1$

Thielavin $B: R_{1}=\mathrm{R}_{2}=\mathrm{CH}_{3} \times 3, \mathrm{OH} \times 1$
Table 1. Concentration required for $50 \%$ inhibition $\left(\mathrm{ID}_{50}\right)$ in (I) the conversion of arachidonic acid (AA) into prostaglandin $\mathrm{H}_{2}\left(\mathrm{PG} \mathrm{H}_{2}\right)$, (II) the conversion of prostaglandin $\mathrm{H}_{2}\left(\mathrm{PG} \mathrm{H}_{2}\right)$ into prostaglandin $\mathrm{E}_{2}$ ( $P G E_{2}$ ), and (III) the conversion of $\mathrm{PG} \mathrm{H}_{2}$ into thromboxane $\mathrm{A}_{2}$.

\begin{tabular}{l|rrr}
\hline \multirow{2}{*}{ Inhibitor } & \multicolumn{3}{|c}{$\mathrm{ID}_{50}(\mu \mathrm{M})$} \\
\cline { 2 - 4 } & (I) & (II) & (III) \\
\hline Thielavin A & 10 & 40 & 150 \\
Thielavin B & 40 & 9 & 350 \\
Indomethacin & 30 & 130 & - \\
Imidazole & - & - & 200 \\
\hline
\end{tabular}

$\mathrm{NaOH}$ - methanol. These spectrum changes with $\mathrm{pH}$ were similar to those obtained with salicylic acid. The IR absorption spectra of thielavin A and B in $\mathrm{KBr}$ disk are shown in Figs. 4 and 5, respectively, indicating the presence of carboxylic acid and benzene moieties. The PMR of these compounds are shown in Figs. 6 and 7, suggesting the presence of aromatic proton due to the signal at 6.8 ppm and 8 methyl residues between $2.1 \sim 2.8 \mathrm{ppm}$. The data further indicated that thielavin A had two methoxy groups due to the signals at 3.9 and $4.1 \mathrm{ppm}$. The CMR of thielavin A and B are shown in Figs. 8 and 9, which suggested the presence of 31 carbons in thielavin A and 29 carbons in thielavin B, respectively. Elementary analysis of thielavin A and B was as follows:
Thielavin A: Found (\%)
C: $65.88, \mathrm{H}: 6.40$
Calcd. for $\mathrm{C}_{31} \mathrm{H}_{34} \mathrm{O}_{10}$
$\mathrm{C}: 65.71, \mathrm{H}: 6.05$
Thielavin B: Found ( $\%)$
C: $64.03, \mathrm{H}: 6.29$
Calcd. for $\mathrm{C}_{29} \mathrm{H}_{30} \mathrm{O}_{10}$
C: $64.68, \mathrm{H}: 5.61$

On the basis of the data presented, the structure of thielavin A and B could be represented as shown in Fig. 10. Further details of structural elucidation will be reported in a subsequent paper.

\section{Biological Activity}

Prostaglandin Synthetase Inhibition

Concentrations required for $50 \%$ inhibition ( $\mathrm{ID}_{50}$ ) of the conversion of arachidonic acid into prostaglandin $\mathrm{H}_{2}(\mathrm{I})$, the conversion of prostaglandin $\mathrm{H}_{2}$ into prostaglandin $\mathrm{E}_{2}$ (II) and thromboxane $\mathrm{A}_{2}$ synthetase (III) are summarized in Table 1.

As indicated, thielavin A most strongly inhibited the conversion of arachidonic acid into $\mathrm{PG}_{2}$ in the reactions tested. On the other hand, thielavin B specifically inhibited the step involving the synthesis of prostaglandin $\mathrm{E}_{2}$ from prostaglandin $\mathrm{H}_{2}$. The inhibitory activity of thielavin $\mathrm{A}$ to the conversion I was far stronger than indomethacin, a drug known as a specific inhibitor of reaction . $^{13)}$ Thielavin $\mathrm{A}$ and $\mathrm{B}$ inhibited the thromboxane $\mathrm{A}_{2}$ synthesis in bovine platelet microsomes by $50 \%$ at a concentration of $150 \mu \mathrm{M}$ and $350 \mu \mathrm{M}$, respectively, values that were comparable to that for imidazole (200 $\mu \mathrm{M})$, a specific inhibitor of III. ${ }^{14)}$

\section{Anti-inflammatory Activity}

Both thielavin A and B showed no significant anti-inflammatory effects on carrageenan-induced oedema in rat foot pad when given orally at a dose $50 \mathrm{mg} / \mathrm{kg}$. When given intravenously, however, thielavin B inhibited this system by $70 \%$ at a dose of $5 \mathrm{mg} / \mathrm{kg}$ while the anti-inflammatory activity was not significant for thielavin $A$ even on intravenous administration at $5 \mathrm{mg} / \mathrm{kg}$. 


\section{Discussion}

The present experiments reveals that two novel depsides thielavin A and B are potent inhibitors of prostaglandin synthesis from arachidonic acid. Although structure of these compounds is closely related to each other (Fig. 10), their mode of action is distinct from each other. Thus, thielavin A specifically inhibits the conversion of arachidonic acid into prostaglandin $\mathrm{H}_{2}$ while thielavin B blocks rather specifically the conversion of the endoperoxide into prostaglandin $E_{2}$. Both compounds might be used as a research tool for studying the regulation of and the mechanism for the synthesis of prostaglandin synthesis.

Differences between thielavins A and B are further seen in their effectiveness on carrageenan-induced oedema on the rat foot pad. Thus thielavin B is effective on intravenous administration while no antiinflammatory activity can be detectable with thielavin A. At present, however, thielavin B is not useful as an anti-inflammatory agent, since it is not active on oral administration. To improve the activity on oral administration, thielavin B should be modified chemically.

\section{Acknowledgments}

The authors are grateful to Dr. E. MisAKA for performing anti-inflammatory experiments and to Dr. M. YAMAZAKI for valuable advice and discussion.

\section{References}

1) VANE, J. R.: Inhibition of prostaglandin synthesis as a mechanism of action for aspirin-like drugs. Nature 231: 232 235, 1971

2) Sмiтh, J. B. \& A. L. Willis: Aspirin selectively inhibits prostaglandin production in human platelets. Nature $231: 235 \sim 237,1971$

3) Ferreria, S. H.; S. Moncada \& J. R. VAne: Indomethacin and aspirin abolish prostaglandin release from the spleen. Nature 231: 237 239, 1971

4) Kitahara, N. \& A. Endo: Xanthocillin X monomethyl ether, a potent inhibitor of prostaglandin biosynthesis. J. Antibiotics 34: 1556 1561, 1981

5) Nugteren, D. H. \& E. Haxelhof: Isolation and properties of intermediates in prostaglandin biosynthesis. Biochem. Biophys. Acta 326: 448 461, 1973

6) Yoshimoto, T.; S. Yамамото, M. Oкuma \& O. Hayaishi: Solubilization and resolution of thromboxane system from microsomes of bovine blood platelets. J. Biol. Chem. 252: $5871 \sim 5874,1977$

7) Ubatuba, F. B. \& S. Moncada: Enzymatic preparation of prostaglandin endoperoxides. Prostaglandins 13: $1055 \sim 1066,1971$

8) Weitzman, I. \& M. Silva-Hutner: Non-keratinous agar media as substrates for the ascigerous state in certain members of the Gymnoasceceae pathogenic for man and animals. Sabouraudia 5: 335 340, 1967

9) Воотн, C.: Studies of Pyrenomycetes. VI. Thielavia, with notes on some allied genera. Mycological Papers, No. 83, 1 15, 1961

10) Udagawa, S.: Notes on some Japanese Ascomycetes. I. Trans. Mycol. Soc. Japan 4: 12 20, 1963

11) Malloch, D. \& R. F. CAIn: The genous Thielavia. Mycologia 65: 1055 1077, 1973

12) ARx, J. A. von: On thielavia and some similar genera of Ascomycetes. Studies in Mycology No. 8, $1 \sim 29$, 1975

13) Miyamoto, T.; N. Ogino, S. Yамамото \& O. Hayaishi: Purification of prostaglandin endoperoxide synthetase from bovine vesicular gland microsomes. J. Biol. Chem. 251: 2629 2636, 1976

14) Moncada, S.; S. Bunting, K. Mullane, P. Thorogood \& J. R. Vane: Imidazole: A selective inhibitor of thromboxane synthetase. Prostaglandins 13: 611 618, 1977 